\title{
Exploration of the interactions between mitigation and solar radiation management in cooperative and non-cooperative international governance settings ${ }^{\text {is }}$
}

\author{
Johannes Emmerling ${ }^{\mathrm{a}, *}$, Massimo Tavoni ${ }^{\mathrm{b}, \mathrm{a}}$ \\ ${ }^{a}$ RFF-CMCC European Institute on Economics and the Environment (EIEE), Via Bergognone, 34, 20144 Milano, Italy \\ ${ }^{\mathrm{b}}$ Politecnico di Milano, Department of Management, Economics and Industrial Engineering, Via Lambruschini 4/b, 20156 Milano, Italy
}

\begin{abstract}
A B S T R A C T

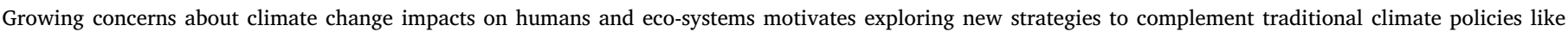

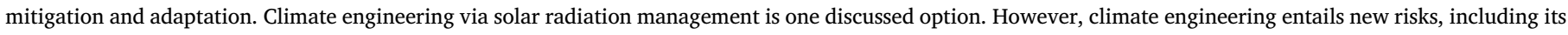

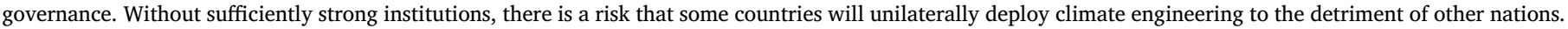

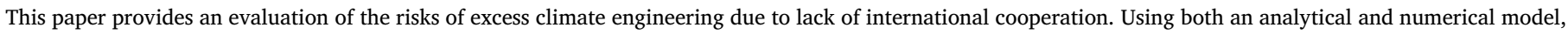

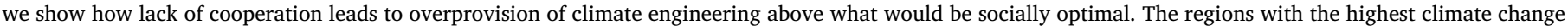

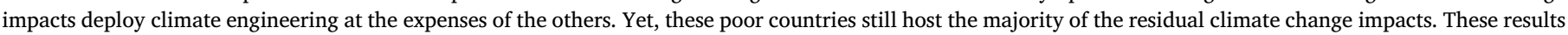
suggest the importance of embedding climate engineering in the international climate policy debate.
\end{abstract}

\section{Introduction}

The slow progress in climate change policies aimed at reducing greenhouse gas emissions is in stark contrast with the estimated impacts of a warmer world. On the one hand, international climate policy has produced little in terms of emission reductions. The Paris climate agreement has been rightly considered an important step forward, due its wide coverage. But the treaty falls short of delivering the emissions cuts needed to stabilize global climate at low temperatures (UNEP, 2010; Rogelj et al., 2015; Aldy et al., 2016). Most importantly, its bottom up architecture is based on voluntary, nationally determined contributions which are inefficient and remain hostage of the political variability, making the agreement particularly fragile. This is in stark contrast with the increased long term ambition in terms of limiting global mean temperature increase, which has been set by the agreement to well below $2{ }^{\circ} \mathrm{C}$, and in the direction of $1.5^{\circ} \mathrm{C}$. Among other things, one of the reason for the tight target is the increased recognition of the high impacts of climate change on economic and ecological systems. Recent estimates suggest significantly higher impacts (Burke et al., 2015), and emphasize non linear damages and tipping points (Lenton et al., 2008).
The discrepancy between what should be done and what is actually observed should not come as a particular surprise. Economists and political scientists has since long warned about the difficulty of establishing a climate agreement which is both effective and stable (Carraro and Siniscalco, 1993; Barrett, 1994). The main issue is the very essence of global warming, namely that it is a global externality and that we lack the institutions able to govern it. This gap in action has fueled the discussion about alternative strategies able to cope with the impacts from climate change. Among these, climate engineering refers to the deliberate and large-scale intervention in the Earth's climatic system with the aim of reducing global warming. One prominent climate engineering option, Solar Radiation Management (SRM), which counteracts the temperature increase by managing incoming solar radiation though means such as sulfur injection in the stratosphere, has become increasingly debated in recent years, see Bickel and Agrawal (2011), Gramstad and Tjøtta (2010), Goes et al. (2011), Moreno-Cruz and Keith (2013), and Heutel et al. (2016). Economists have carried out cost benefit assessments of climate engineering, with mixed results (see Klepper and Rickels (2012) or Barrett (2008) for an overview). The literature shows that climate engineering can provide a viable strategy if climate change is very harmful in the future (Bickel and Agrawal,

\footnotetext{
The authors would like to thank Juan Moreno-Cruz, Martin Quaas, Elmar Kriegler, Martin Weitzman, Marco Casari, four anonymous referees, and participants of

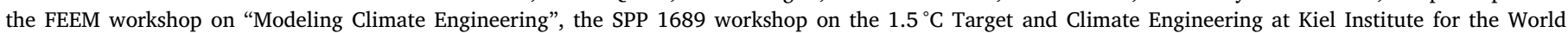

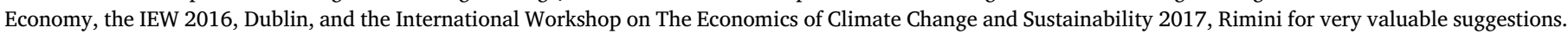
The usual caveat applies.

* Corresponding author.

E-mail address: johannes.emmerling@eiee.org (J. Emmerling).
} 
2011), but also that its uncertainties (about its effectiveness, spatial distributions, and side-effects) are such that it cannot substitute mitigation (Moreno-Cruz et al., 2012; Emmerling and Tavoni, 2017). The academic dispute is mostly driven by assumptions about climate engineering costs and benefits, which are very hard to quantify (Sterck, 2011). However, a central element raised by climate engineering relates to international governance.

Climate engineering raises specific governance issues (Victor et al., 2009), and currently there is a lack of an agreed framework to deal with climate engineering. The mere existence of climate engineering might justify lowered effort to curb greenhouse gas emissions, leading to a possible moral hazard. Although the potential of SRM to substitute or complement mitigation measures has been mostly assessed in the global context, its impacts on the strategic incentives in the context of climate negotiations are particularly relevant, as originally suggested by Schelling (1996). Virgoe (2008) discusses several potential governance schemes to deal with the unilateral and non-cooperative incentives that can arise from SRM, either involving the United Nations, single nations or coalitions. Overall, the strategic nature and regional heterogeneity provide incentives for the use of SRM which might go against the global good. Indeed, Rayner et al. (2013) suggested the so-called "Oxford principles" as a first guidance for governance and research on SRM by countries including its "regulation as public good" as first principle (the other four principles include public participation in geoengineering decision-making, disclosure of geoengineering research and open publication of results, independent assessment of impacts, and governance before deployment). Therefore, the possibility of unilateral implementation needs to be considered and assessed (Rabitz, 2016).

This paper aims at providing an appraisal of the risk of overprovision of climate engineering as a result of lack of international cooperation. In order to do so, we first lay out a conceptual framework for thinking about climate engineering under non-cooperative and cooperative settings. Then, we use a calibrated energy-climate-economy model for numerical evaluation and sensitivity analysis. In both models, each region decides how much to abate GHG emissions and how much SRM to do. Global emissions generate climate change, which leads to region-specific economic losses. SRM implementation also leads to damages, thus introducing an additional externality. By comparing the global optimum and Nash equilibria, we explore the interactions between mitigation and climate engineering under cooperative and noncooperative governance settings respectively.

This allows evaluating the risks of under-provision of mitigation and overprovision of climate engineering. The paper is related to the an argument recently put forward (Weitzman, 2015): namely, that climate engineering is so relatively cheap (Barrett, 2008), that it might be deployed unilaterally by one country to the detriment of others. Weitzman has dubbed this new form of strategic interaction as 'free driving'. The familiar free riding externality, which is at the basis of the climate change dilemma, is thus extended to the case of climate engineering: if free riding leads to under-provision of emission reductions, free driving could lead to an over provision of climate engineering above the global social optimum. Note that while Weitzman motivates free driving as a response to the lack of emission reductions, in his model the only climate strategy is climate engineering. Free driving occurs as a result of countries' different preferences for the optimal temperature. In our setting, on the other hand, over-provision of climate engineering occurs because of the asymmetry of climate damages and damages from deploying climate engineering itself. However, our set-up does not allow to disentangle the extent to which the overprovision of climate engineering is due to lack of cooperation on emission reductions, and to free driving as a result of different preferences for the level of SRM. In the numerical modeling part, we jointly evaluate the double free-riding and free-driving externalities. Before doing so, we outline an analytical model which captures the first effect resulting from the interaction of climate and SRM damages.

\section{A game-theoretic framework}

Given the strategic implications of climate engineering, it is useful to lay out a simple game theoretic model to help framing the problem, before moving to the calibrated numerical analysis. Several dynamic games have been proposed in the literature. Ricke et al. (2013) provide a numerical assessment of coalition formation in a two-stage game, and show that regional differences in climate outcomes create strategic incentives to form coalitions that are as small as possible, while still powerful enough to deploy solar geoengineering. Millard-Ball (2012) considers the formation of a climate agreement about mitigation, with individual decisions to implement SRM. He shows that a credible threat of unilateral geoengineering may strengthen global abatement and climate cooperation. Urpelainen (2012) considers a simple two period deterministic model, showing that the availability for SRM in the future can increase mitigation effort at present, since it can hurt other countries. Moreno-Cruz (2015) also studies the dynamic nature of the SRMMitigation trade-off in a sequential two-stage game, and finds that highly asymmetric impacts are an important driver of potential overprovision of SRM. Manoussi and Xepapadeas (2015) study a differential game between two heterogeneous countries, also finding countries with higher benefits/lower costs will engage more in using SRM. Goeschl et al. (2013) analyze long-term inter generational trade-offs due to the possibility of SRM, while Quaas et al. (2017) consider the dynamics including the non-cooperative decision on whether or not to engage in research on SRM in the first place. Moreno-Cruz and Smulders (2017) also develop optimal and non-cooperative SRM facing impacts from temperature increase and carbon concentrations (using a more complex carbon cycle) in an one-stage game, which is the most related to our approach.

Here, we follow Barrett (2008) and Weitzman (2015) and propose a game-theoretic model of optimal abatement and SRM policies. The strategy set is $\left\{a_{i}, s_{i}\right\}$-abatement $a_{i}$ and climate engineering $s_{i}$ indexed by region $i=1, \ldots, N$. The model is static, a major simplification. However, we can interpret the variables as cumulative values, with $a$ and $s$ being the sum of abated emissions and deployed SRM over the century. Indeed, we will use these definitions for calibrating the analytical model (see also Appendix). We leave the dynamics to the numerical analysis in the second part of the paper. We use a standard cost-benefit analysis approach, whereby each country minimizes total costs from deployment of abatement and SRM technologies, as well as impacts from global warming and SRM deployment.

For modeling the global climate, we use the carbon budget approach (Urpelainen, 2012; Matthews et al., 2009) and express the global mean temperature change $\Delta T$ as a linear function of both total cumulative emissions ( $e$ ) and SRM $(s)$. Cumulative emissions are the sum of projected business as usual (BAU) emissions without any climate policy $\left(e_{j}^{\text {bau }}\right)$ in region $j$ over all regions $N$. SRM directly lowers global temperature, proportionally to the global SRM deployment. We denote by $\gamma$ the transient climate response (Matthews et al., 2009), that is, the change in mean temperature due to cumulative carbon emissions, and by $\lambda$ the effectiveness of SRM to reduce temperature, so that global mean temperature increase is given by (see also Appendix A for details):

$\Delta T=\gamma \sum_{j=1}^{N}\left(e_{j}^{\text {bau }}-a_{j}\right)-\lambda \sum_{j=1}^{N} s_{j}$

Each country $i$ solves the problem of minimizing the total costs $\left(T C_{i}\right)$ from abatement $\left(C_{A}\right)$, SRM deployment $\left(C_{S}\right)$, climate change impacts $\left(D_{T}\right)$ and SRM impacts $\left(D_{s}\right)$ given by:

$\mathrm{TC}_{i}=C_{\mathrm{Ai}}\left(a_{i}\right)+C_{\mathrm{Si}}\left(s_{i}\right)+D_{\mathrm{Ti}}\left(\gamma \sum_{j=1}^{N}\left(e_{j}^{\text {bau }}-a_{j}\right)-\lambda \sum_{j=1}^{N} s_{j}\right)+D_{\mathrm{Si}}\left(\sum_{j=1}^{N} s_{j}\right)$

We can derive the first order conditions under both the Nash equilibrium and global optimum, as shown in Appendix A for the case of a fully quadratic specification of costs and impacts. We focus on the 
symmetric case of identical countries to show the differences between cooperative and non-cooperative solutions and pin-point only the consequences of lack of cooperation on climate (For free driving to exist, one also would need asymmetry on climate change impacts, as done in the numerical exercise). More general cases are discussed in Appendix. Naming marginal damages from global temperature increase $\tau$, mitigation costs $\alpha$, impacts from SRM $\theta$ and SRM implementation costs $\sigma$, we find that for each country the optimal level of SRM under cooperation is

$S_{\text {sym }}^{\text {coop }}=\frac{1 / N}{\lambda+\frac{\gamma}{\lambda}\left(\frac{N^{2} \theta+\sigma}{\alpha}+\frac{N^{2} \theta+\sigma}{\gamma \tau N^{2}}\right)}\left(\gamma \sum_{j=1}^{N} e_{j}^{\text {bau }}\right)$

while in the non-cooperative Nash equilibrium it is given by

$S_{\mathrm{sym}}^{\text {strategic }}=\frac{1 / N}{\lambda+\frac{\gamma}{\lambda}\left(\frac{N \theta+\sigma}{\alpha}+\frac{N \theta+\sigma}{\gamma \tau N}\right)}\left(\gamma \sum_{j=1}^{N} e_{j}^{\text {bau }}\right)$.

SRM deployment is driven by the efficacy to compensate global warming $\left(\frac{\gamma}{\lambda}\right)$ and four terms comparing costs and benefits -two of which depend on $N$. For $N=1$, SRM deployment is the same under the noncooperative and cooperative cases, and as expected there is no overprovision of climate engineering. When $N>1$, two effects drive a wedge between the cooperative and non-cooperative solution: the first term in the parenthesis in the denominator of (1) and (2) represents the SRM overprovision, a function of the costs of SRM (implementation costs $\sigma$ and impacts $\theta$ ) compared to mitigation costs $(\alpha)$. This term differs between cooperative and non-cooperative solutions: in the cooperative case, the impact of SRM in all regions are internalized, hence the factor $N^{2}$ instead of $N$. This leads to a wedge in SRM deployment between non-cooperative and cooperative cases, which grows in $N$. The second term in the parenthesis compares both externalities, climate and SRM, and is of second order compared to the first effect: since the climate externality scales in $N$ both for climate impacts and SRM impacts, here $N$ cancels in the numerator and denominator, while only private SRM costs $(\sigma)$ do not scale in $N$. Thus, if $N$ increases, the second term leads to higher SRM in the cooperative compared to the non-cooperative solution. Note however that this effect is linear in the marginal cost of SRM $\sigma$. That is, for comparably small implementation costs compared to it potential impacts, i.e., $\sigma \ll \theta$, this effect becomes negligible and the SRM overprovision due to the first term effect dominates.

Fig. (1) provides a graphical illustration of the climate engineering overprovision, measured by the ratio of SRM in the non-cooperative case over what socially optimal. Results are based on a calibration to common projections of emissions, available parameters about cost and

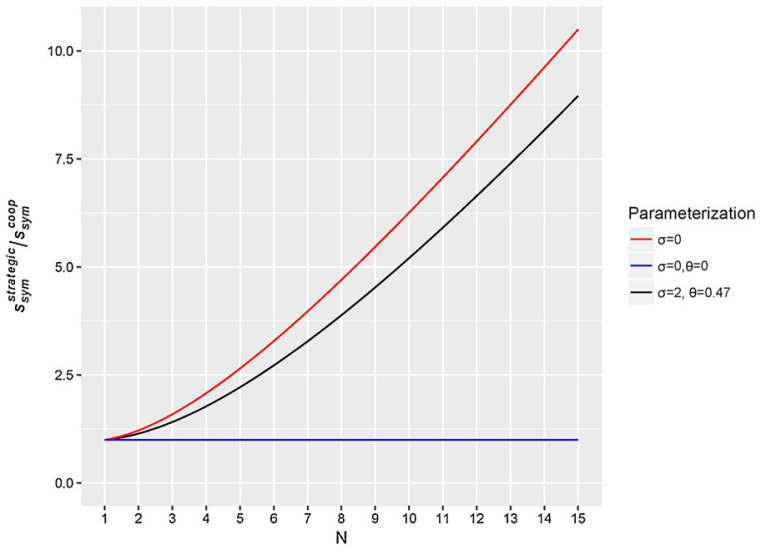

Fig. 1. Ratio of SRM deployment in non-cooperative over cooperative cases as a function of the number of countries $N$, for different parametrizations. $\sigma=\mathrm{SRM}$ marginal investment costs; $\theta=$ SRM marginal impacts. effectiveness of SRM, and stylized facts about climate and SRM impacts (see Appendix A for details). The picture shows that when the costs of climate engineering $(\sigma)$ are zero or sufficiently low, too much climate engineering occurs. The overprovision increases in the number of regions almost linearly (especially for $N>5$ ). When climate engineering has no adverse impacts $(\theta=0)$, there is no difference in cooperative and non-cooperative solutions and SRM is fully deployed in both cases. The results are illustrative, given the simplifying assumptions made. For example, previous analysis (Millard-Ball, 2012; Moreno-Cruz, 2015) has shown that under asymmetric impacts of SRM climate engineering might even spur emission abatement and facilitate the formation of a self enforcing climate agreement. We explore the case of asymmetric SRM impacts with the numerical analysis.

\section{Numerical quantification}

The previous section has indicated that too much climate engineering occurs in the absence of climate cooperation, and that the effect grows in the number of countries. In order to better evaluate the overprovision effect, we need to move to a more realistic model. We employ a calibrated energy-economy-climate model which optimizes investments in both climate engineering and mitigation in a setting with strategic interactions among nations and asymmetric climate change impacts. We compare the case of no cooperation (Nash) to the one with full cooperation, representing the world social optimum where countries cooperate on the externalities resulting from both emissions and climate engineering. The gap between these two climate architecture allows us to estimate free driving and free riding simultaneously, but not to tell them apart. We use the game theoretic integrated assessment model WITCH (Bosetti et al., 2009; Emmerling et al., 2016), a numerical model which has been extensively used to evaluate climate mitigation policies. The model integrates the energy sector into a dynamic optimal growth economic model, and runs for the whole century at five year time steps. WITCH divides the world into 13 regions/countries (see Fig. S1 in Appendix B for a map and more details). Although 13 regions/countries do not permit sufficiently disaggregated analysis at the individual country level, all the major emitters are represented. Similarly to the analytical model, we use a cost benefit framework in which the cost of acting on climate change either via mitigation or climate engineering - is weighted against the benefits of lowering global temperature. Climate change impacts are a region-specific quadratic function of global temperature, with regionally differentiated and calibrated impacts. Data for calibration comes from the estimates of key market based impact categories such as energy demand, sea level rise, agriculture, ecosystems losses and health compiled by Bosello and De Cian (2014). Fig. S2 and Table S1 in Appendix A provide details about the climate impact function values and calibration. The quadratic exponent follows the damage literature, in particular the DICE model (Nordhaus, 2014, 2017). However, given the uncertainties characterizing climate change damages we perform a sensitivity analysis with a "high damage" scenario, where the damage function is steeper (with an exponent of 2.8 instead of 2), resulting in global impacts from global warming (without adaptation) at $2.5^{\circ} \mathrm{C}$ warming by 2100 of $5.3 \%$ of GDP compared to $3.1 \%$ of GDP in the baseline assumption.

We expand the standard version of the model to include an SRM module, which accounts for operational costs, effectiveness in compensating temperature as well as social and environmental impacts of climate engineering. See Appendix B (SRM Module section) for the module description and calibration. The first two issues are relatively well understood in the literature, and we use a linear cost function and proportional compensation of radiative forcing to SRM. As a sensitivity analysis, we consider a case with zero implementation costs. Results are essentially unchanged (see Fig. S5 in Appendix). As for the indirect, external costs of SRM - which include possible damage to the ozone layer, side effects of the implementation itself, as well as region-specific 
impacts such as increased droughts and other eco-system impacts (Russell et al., 2012), these are currently unknown and profoundly uncertain (Aaheim et al., 2015). We assume them to be global, and follow Goes et al. (2011), who suggest economic impacts of a fixed percentage of consumption for a given amount of SRM. Specifically, they assume 3\% consumption loss for SRM compensating each every $3.5 \mathrm{~W} / \mathrm{m}^{2}$ of forcing. These estimates are admittedly fragile, with limited or non-existent empirical basis. We therefore examine a variety of sensitivity analysis, with SRM damages of $0.1 \%, 1 \%, 2 \%, 4 \%, 5 \%$ (as suggested by Goes et al. (2011), as well as a higher value of $10 \%$. We assume SRM damages are the same across regions, but also explore a case in which SRM and climate impacts are collinear, and calibrated to be the same for $2.5^{\circ} \mathrm{C}$ of warming. Finally, in order to capture a specific consequence of SRM regarding the potential impact from abrupt warming or cooling, which is not covered by standard damage functions, we assume a damage term coming from temperature variation (as opposed to level) and calibrated on Lempert et al. (2000). We further assume that SRM will be available from mid century onward, since SRM still needs to be further researched before being deployed at scale. This is an arbitrary assumption, since earlier SRM deployment might be possible. Previous work with the same model has shown this not to be an important parameter (Emmerling and Tavoni, 2017).

\subsection{Global overprovision of climate engineering}

The calibrated energy-climate model allows evaluating the risk of too much climate engineering. To do so, we run a two-by-two scenario matrix with cooperation and SRM availability as dimensions. This yields four scenarios, in addition to a counterfactual business as usual without climate change and SRM. Fig. 2 provides the main global results in terms of cumulative emission mitigation (left panel) and SRM deployment (right panel). Ranges show the sensitivity to SRM impacts (spanning \pm 2 of GDP around our central value of $3 \%$, i.e., from 1 to $5 \%$ of GDP for compensating $3.5 \mathrm{~W} / \mathrm{m}^{2}$ of radiative forcing). The left panel highlights a major decline in emission reduction when moving from a cooperative setting to a non-cooperative one. This is the familiar issue of free riding, which limits the incentives to reduce $\mathrm{CO}_{2}$ emissions when countries do not cooperate for the public good but rather act in their own interest. Cumulatively over the century, free riding reduces mitigation by 85.4 and 82.9 for the cases with and without SRM respectively. When climate engineering is available (dashed lines), we

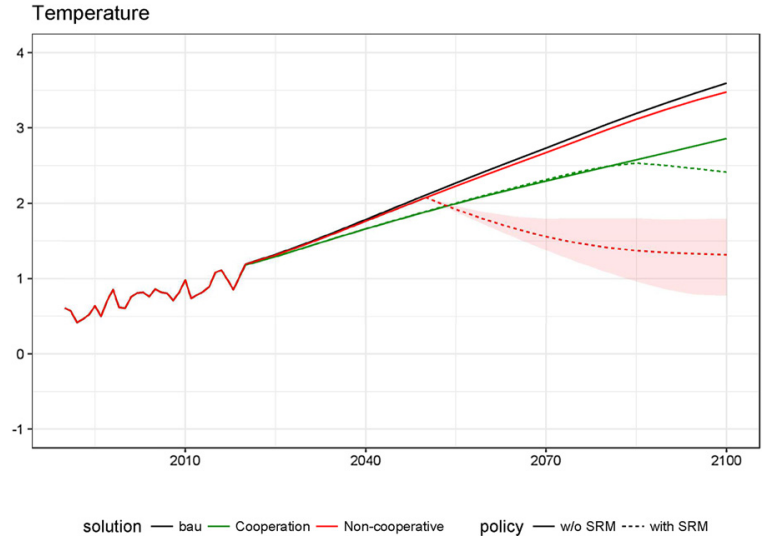

Fig. 3. Global temperature over the 21st century (compared to preindustrial levels) across scenarios (shaded area shows sensitivity analyses for SRM impacts for the range $1-5 \%$ of GDP for compensating $3.5 \mathrm{~W} / \mathrm{m}^{2}$ of radiative forcing).

notice a reduction in mitigation, both in the case of cooperation and in the non-cooperative one. That is, we have evidence of SRM crowding out mitigation effort. This moral hazard effect has been often described as one of the main rationale for banning SRM from the set of climate strategies (McLaren, 2016). While our evaluation indicates some reduction in mitigation due to SRM, quantitatively the crowding out of mitigation we find is small compared to the SRM overprovision.

The right panel reports deployment of SRM in the scenarios where this is available. The chart provides evidence of significant overprovision of climate engineering: cumulatively over the second half of the century, SRM is over-deployed by a factor of 8 in the non-cooperative case $(95.5 \mathrm{TgS})$ with the respect to the socially desirable level (12.0TgS). Furthermore, SRM is deployed significantly later (2075 versus 2050 , the first available date) under the cooperative case. The magnitude of this effect confirms the quasi linear predictions of the analytical model presented in the previous section. All in all, the SRM over-provision appears to be of a similar magnitude than the underprovision of GHG mitigation.

Fig. 3 shows the implications for the global mean temperature increase, while in Appendix in Fig. S6 we show the $\mathrm{CO}_{2}$ concentrations. Without SRM, end of century temperature would increase by $2.8^{\circ} \mathrm{C}$ with cooperation and by $3.5^{\circ} \mathrm{C}$ without cooperation. That is, SRM - by

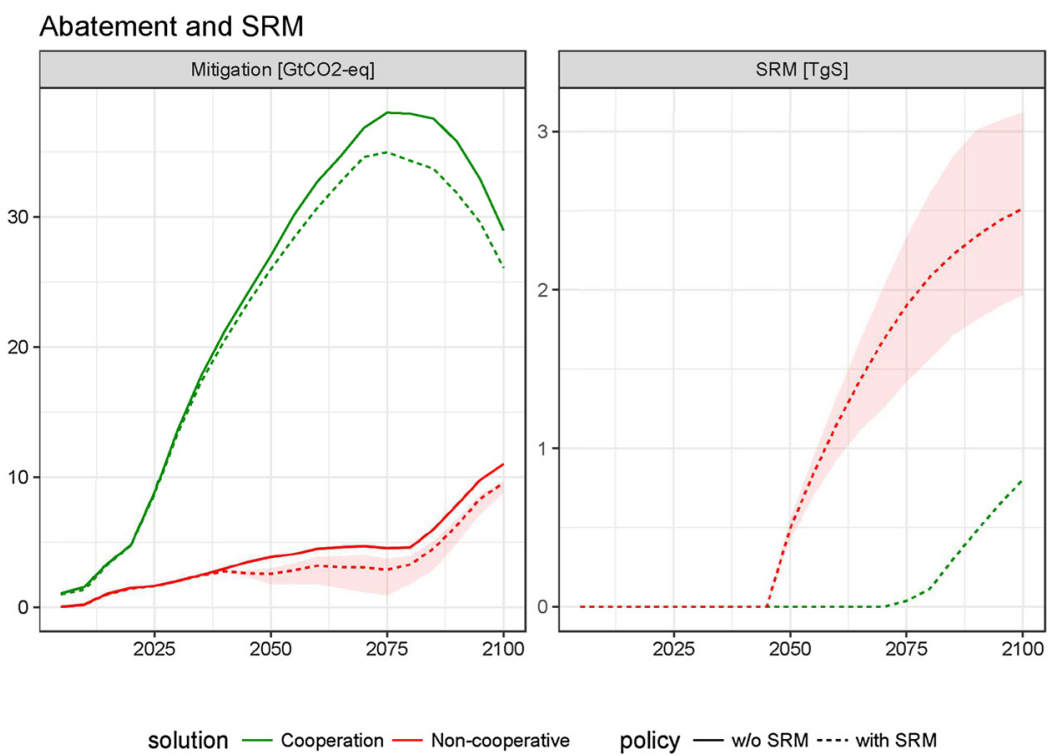

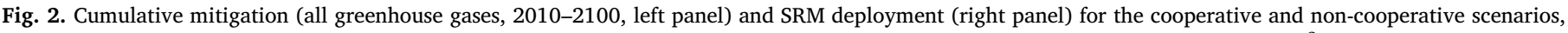
with and without SRM (shaded area shows sensitivity analyses for SRM impacts for the range $1-5 \%$ of GDP for compensating $3.5 \mathrm{~W} / \mathrm{m}^{2}$ of radiative forcing). 
weakening mitigation efforts - increases end of century temperature by about $0.7^{\circ} \mathrm{C}$, bringing it very close to the BAU case of no climate damages. Availability of SRM allows to decrease temperature moderately under cooperation (from $2.8^{\circ} \mathrm{C}$ to $2.4^{\circ} \mathrm{C}$ ), but dramatically under non cooperation (from $3.5^{\circ} \mathrm{C}$ to $1.1{ }^{\circ} \mathrm{C}$ ). It is worth noticing how globally sub-optimal this outcome is. In a world governed by supra-national institutions which maximize global welfare by internalizing the impacts of climate change and SRM, SRM will be used to lower temperature only late in the century and moderately, by less than $0.5^{\circ} \mathrm{C}$. In a world characterized by national interests and no coordination, SRM would be used excessively $\left(2.4^{\circ} \mathrm{C}\right.$ of cooling) and from the onset (year 2050).

Since deploying SRM generates global external costs, the over-provision of SRM documented in the previous chart can negatively influence global welfare, outweighing the benefits of reduced global warming. This is indeed what we find to be the case. Policy costs are higher in the non-cooperative scenarios, and increase when SRM is made available (GDP losses of $3.2 \%$ with SRM and $2.8 \%$ without). On the contrary, cooperation lowers policy costs, and these are not affected by whether SRM is available or not (GDP losses of $0.6 \%$ both with and without SRM). The global economic losses from lack of cooperation $(2.8 \%-0.6 \%=2.2 \%)$ further increase with SRM $(3.2 \%-0.6 \%=2.6 \%)$. Thus, SRM seems to have a heavily one-sided effect more greatly impacting the non-cooperative setting negatively. This highlights that when evaluating SRM as an alternative to mitigation (one of the key issues examined in the literature, see Moreno-Cruz and Smulders (2017)) a non-cooperative setting should be employed.

Decomposing the difference in policy costs between the runs with and without SRM over time, Fig. 4 shows that climate engineering external costs outweigh the benefits of lower temperature throughout all the century. The gap between reduced climate impacts (standard and gradient) and external damages of climate engineering (SRM impacts) are much bigger for the non-cooperative scenarios. This is a result of the larger deployment of SRM in absence of cooperation. The other costs components (SRM and residual, including abatement) appear to have second order effects. This suggests that the relative appeal of SRM and mitigation largely depends on the climate and SRM impacts. Both are very difficult to estimate.

\subsection{Regional results}

So far we have looked at the global picture. Let's now turn to the disaggregated regional results coming from the integrated model,

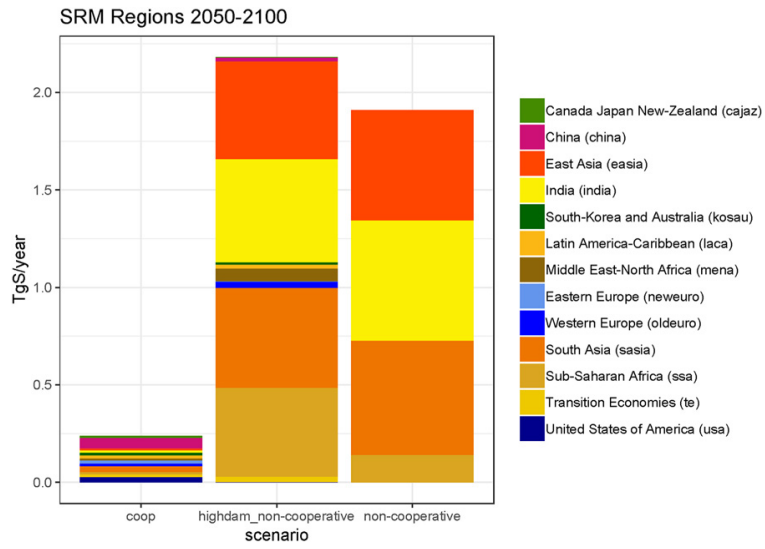

Fig. 5. Regional distribution of SRM. Cumulative (2050-2100) SRM deployment across regions for the cooperative case (left bar), and the non-cooperative cases with normal and high climate impacts (right and central bars). For the definition of the regions, see Fig. S1 in Appendix B.

which divides the world into 13 macro-economic regions. Fig. 5 reports the regional distribution of SRM deployment. The cooperative scenario shows a low level of SRM - as documented before. Moreover, given that we do not consider equity weights of regions and the implementation costs of SRM are linear (see Appendix B), the distribution between regions does not matter and the results presented here prescribe an even split among regions. The most interesting results come from the noncooperative cases, which will be the focus of the regional analysis from here onward. Finding a unique solution to this problem is not a trivial task, since (numerous) multiple equilibria exist. We use an approximation method where first we identify bounds for SRM based on unilateral deployment (e.g. one region at the time), which we use as constraints when running the non-cooperative solution where all countries can engage in SRM. In Appendix C the approximation algorithm is discussed in more detail. Results in Fig. 5 indicate that SRM would be deployed in few regions, mainly in Asia and Africa. When assuming that only one country at a time can deploy SRM, the same subset of countries deploy SRM (see Fig. S3 in Appendix D). This implementation method reflects the modeling of Weitzman's stylized freeriding model where only one region deploys SRM, while the equilibrium presented here represents more realistic regional distribution to the deployment of SRM. Yet, it is noteworthy that many equilibria exist

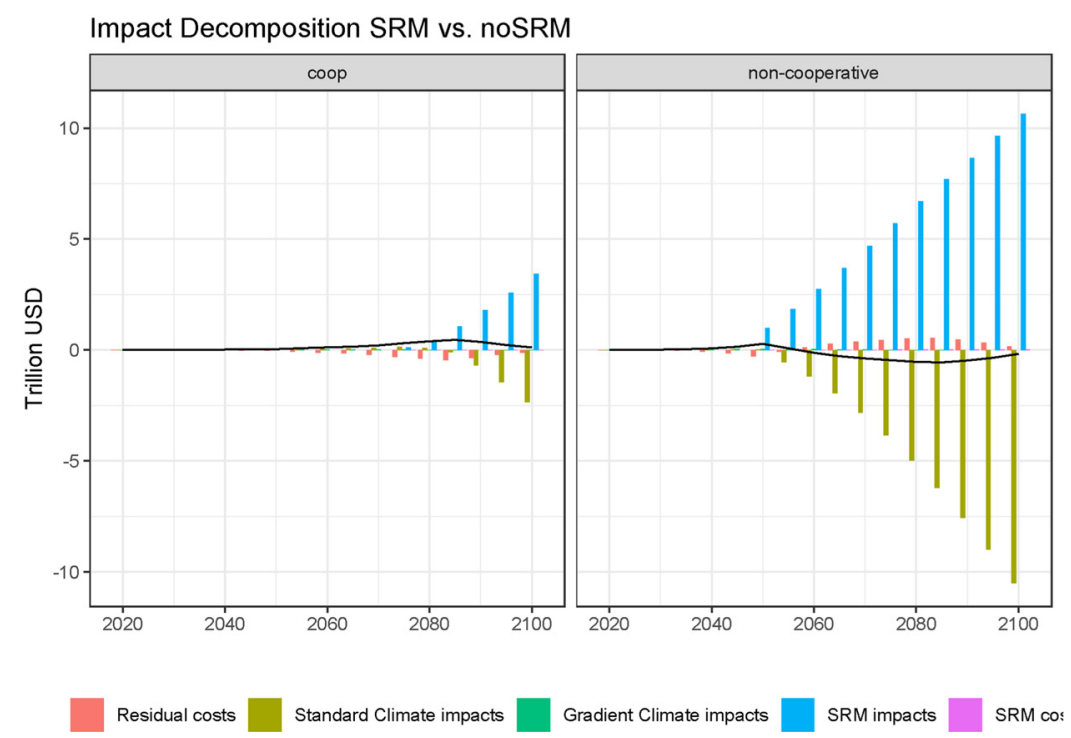

Fig. 4. Global welfare impacts of climate engineering measured as policy costs difference between "with SRM" and "w/o SRM" scenarios decomposed by source and over time. 
conceptually, which would lead to the same global climate outcomes and regional impacts. The only difference across regions would consist in the distribution of the (minor) SRM implementation costs. The total SRM and its regional distribution appear to be relatively similar when assuming higher climate change impacts, shown in the same chart.

We also performed sensitivity analysis with respect to the damages of SRM, which are highly uncertain - see Fig. S4 in Appendix D. We let SRM impacts vary from $0.1 \%$ all the way to $10 \%$ of consumption losses for every $3.5 \mathrm{~W} / \mathrm{m}^{2}$ of forcing offset. Total SRM scales approximately linearly with the external impacts of SRM, in the expected direction of lower impacts leading to more SRM. Furthermore, our central specification assumes symmetric SRM impacts, given the limited knowledge about their values. In fact, this might well be not the case, and previous theoretical contributions have shown that asymmetric SRM damages might lead to less SRM and more abatement (Millard-Ball, 2012; Moreno-Cruz, 2015). To test this, we ran an additional case in which SRM and climate impacts are collinear, and equal for global warming of $2.5^{\circ} \mathrm{C}$. Results (Fig. S5 in Appendix) show as expected that when climate change and SRM impacts are positively correlated, less SRM is deployed. Nonetheless, even in this case significant quantities of sulfur are injected in the atmosphere, and mostly by the same set of regions. We also looked at the regional changes in mitigation patterns, see Fig. S7 in Appendix. In the non-cooperative case, abatement decreases slightly when SRM is available, confirming the global results that free riding seems to be of relatively less important than the overprovision of SRM.

The rationale for the regional distribution of SRM is shown in Fig. 6. Developing Asia and Africa show the highest climate benefits, in terms of reduced impacts from climate change. Indeed, these are the regions which would suffer the most from climate change according to the climate impact function 9. Abstracting from the side effects of climate engineering, the global climate benefits of lowering temperature would be substantial, from an expected economic loss in 2100 of around 14 trillion USD without SRM, down to 3 trillion with SRM. Of these almost 11 trillion USD in reduced climate impacts, 7.5 trillion USD would accrue to the regions deploying SRM in Asia and Africa. Still, these countries would experience more than half of the total residual climate damages. Moreover, lowering global temperature via SRM comes at the cost of high impacts from SRM, shown in Fig. 6 as a blue line. Note that in the main specification, SRM impacts are equal across countries, and since we report net present values, the blue line is not exactly equal across regions given a different timing of SRM implementation across regions.

To further delve into the strategic aspects of SRM, we evaluate which regions are gaining or losing from its availability. Fig. 7 plots

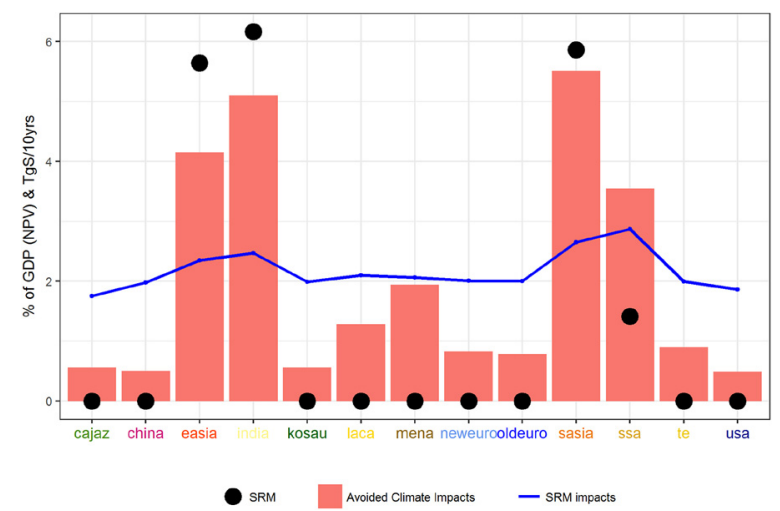

Fig. 6. Avoided climate impacts due to SRM and SRM impacts (in \% of GDP NPV, 3\% discount rate), as well as SRM deployment (TgS per decade), for the non-cooperative scenarios, 2050-2100. (For interpretation of the references to color in the citation of this figure, the reader is referred to the web version of this article.)

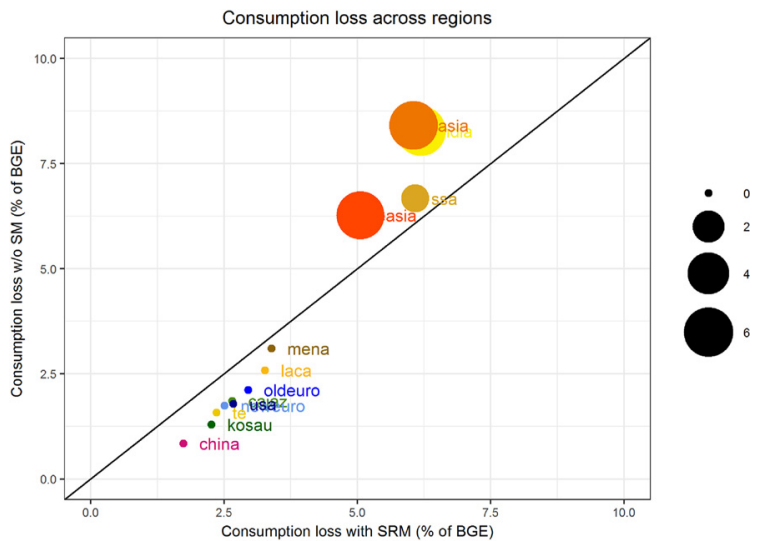

Welfare across regions, BGE

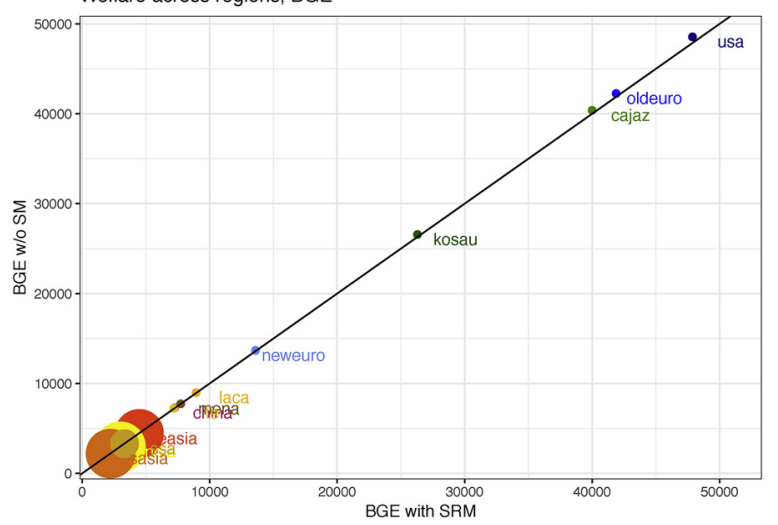

Fig. 7. Consumption losses (NPV, $3 \%$ discount rate, upper panel) and welfare levels (lower panel) with and without SRM across regions for the non-cooperative scenarios. The size of the circles is proportional to the average SRM deployment (in $\mathrm{TgS}$ per decade).

welfare and consumption losses both with and without SRM for the 13 regions. The diagonal line separates regions winning from SRM (above) from those loosing (below). The chart indicates that the countries which do deploy SRM - in Asia and Africa - gain from doing so, at the expenses of all other regions. However, total welfare (lower panel, measures as Balanced Growth Equivalent (BGE), see Anthoff and Tol, 2009) is not significantly affected, and the regions supporting SRM remain among the poorest in the world, both because of general economic factors as well due to the higher impacts of climate change in these countries.

\section{Conclusion}

The analytical and numerical modeling exercises described in this paper document a possible risk of excess climate engineering. Under non-cooperation, too much climate engineering is deployed, temperature falls below the optimal value, and the side effects of climate engineering outweigh the benefits of lower climate impacts, with negative global welfare impacts. The regional results indicate that the countries with higher expected impacts from climate change would be the ones deploying climate engineering at the expenses of the rest of the World. Yet, these poor countries would still host the majority of the residual climate change impacts. These results bear important repercussions for international climate policy. Climate engineering has been often described as a possible solution in case climate negotiations over mitigation fail. Indeed, its cost effectiveness in reducing global temperature and the ability to do so in rapid time is unparalleled. However, it is vital that climate engineering is discussed and negotiated within the few existing supra-national institutions and possibly jointly with mitigation measures. In such a setting, our model has shown that climate 
engineering could provide a valuable complement to emission mitigation, lowering global temperature by $0.4{ }^{\circ} \mathrm{C}$. On the other hand, failure to collectively manage climate engineering could results in too much climate engineering, and to a total welfare loss as the benefits from a less hot planet would be more than offset by the damages inflicted by SRM deployment.

The underlying analysis is greatly simplified, especially for what concerns countries' retaliatory measures and political influence. For example, counteracting measures against SRM aimed at undoing the temperature masking could be deployed, triggering an SRM war with unclear consequences. Although our results appear to be robust to sensitivity analysis, more work needs to quantify the interplay between climate change and SRM impacts. The latter are especially not well understood, and will require further research before a real quantification can be carried out (Irvine et al., 2017). Notably, if SRM impacts turn out to be much lower than currently considered, the welfare effects could be different. The most well-understood major side effects of SRM are the effects on the hydrological cycle, and damages from ocean acidification. Current damage functions assume that impacts from temperature and $\mathrm{CO} 2$ are proportional (as we assumed here), but climate engineering challenges this assumption by breaking the temperature- $\mathrm{CO}_{2}$ relation (Oschlies et al., 2017). More detailed geographic resolution at the level of countries is also warranted, since this is an important variable as shown in the analytical model results. Doing so might further emphasize the findings of this article. In this paper, we have neglected uncertainties and risks related to climate engineering characteristics. Previous work, including also work with the IAM WITCH, has shown this to be an important driver of SRM viability (Emmerling and Tavoni, 2017; Moreno-Cruz and Keith, 2013).

Despite these (and other) limitations, the analysis presented here has highlighted the relevance of strategic considerations when evaluating climate engineering as a climate control strategy. The governance challenges raised by climate engineering are enormous, and should be guiding research and policy alike.

\section{Appendix A. Supplementary Data}

Supplementary data associated with this article can be found, in the online version, at https://doi.org/10.1016/j.gloenvcha.2018.10.006.

\section{References}

Aaheim, A., Romstad, B., Wei, T., Kristjánsson, J.E., Muri, H., Niemeier, U., Schmidt, H., 2015. An economic evaluation of solar radiation management. Sci. Total Environ. 532, 61-69. URL: http://www.sciencedirect.com/science/article/pii/ S0048969715301649.

Aldy, J., Pizer, W., Tavoni, M., Reis, L.A., Akimoto, K., Blanford, G., Carraro, C., Clarke, L.E., Edmonds, J., Iyer, G.C., McJeon, H.C., Richels, R., Rose, S., Sano, F., 2016. Economic tools to promote transparency and comparability in the Paris Agreement. Nat. Clim. Change 6 (11), 1000-1004. URL: http://www.nature.com/nclimate/ journal/v6/n11/full/nclimate3106.html.

Anthoff, D., Tol, R.S.J., 2009. The impact of climate change on the balanced growth equivalent: an application of FUND. Environ. Resour. Econ. 43 (3), 351-367. URL: http://link.springer.com/10.1007/s10640-009-9269-5.

Barrett, S., 1994. Self-enforcing international environmental agreements. Oxf. Econ. Pap. 46, 878-894. URL: http://www.jstor.org/stable/2663505.

Barrett, S., 2008. The incredible economics of geoengineering. Environ. Resour. Econ. 39 (1), 45-54. URL: http://www.springerlink.com/content/a91294x25w065vk3/ abstract/.

Bickel, J., Agrawal, S., 2011. Reexamining the Economics of Aerosol Geoengineering.

Bosello, F., De Cian, E., 2014. Documentation on the development of damage functions and adaptation module in the WITCH model. Tech. Rep. RP0228. Centro EuroMediterraneo sui Cambiamenti Climatici.

Bosetti, V., Tavoni, M., Cian, E.D., Sgobbi, A., 2009. The 2008 WITCH Model: New Model Features and Baseline. Working Paper 2009.85. Fondazione Eni Enrico Mattei. URL: http://ideas.repec.org/p/fem/femwpa/2009.85.html.

Burke, M., Hsiang, S.M., Miguel, E., 2015. Global non-linear effect of temperature on economic production. Nature 527 (7577), 235-239. URL: http://www.nature.com/ nature/journal/v527/n7577/full/nature15725.html.

Carraro, C., Siniscalco, D., 1993. Strategies for the international protection of the environment. J. Public Econ. 52 (3), 309-328. URL: http://www.sciencedirect.com/ science/article/pii/004727279390037T.

Emmerling, J., Drouet, L., Reis, L.A., Bevione, M., Berger, L., Bosetti, V., Carrara, S., Cian,
E.D., D’Aertrycke, G.D.M., Longden, T., Malpede, M., Marangoni, G., Sferra, F., Tavoni, M., Witajewski-Baltvilks, J., Havlik, P., 2016. The WITCH 2016 Model Documentation and Implementation of the Shared Socioeconomic Pathways. Working Paper 2016.42. Fondazione Eni Enrico Mattei. URL: https://ideas.repec.org/ p/fem/femwpa/2016.42.html.

Emmerling, J., Tavoni, M., 2017. Climate Engineering and Abatement: A 'Flat' Relationship Under Uncertainty. Environmental and Resource Economics. pp. 1-21. URL: http://link.springer.com/article/10.1007/s10640-016-0104-5.

Goes, M., Tuana, N., Keller, K., 2011. The economics (or lack thereof) of aerosol geoengineering. Clim. Change 109 (3-4), 719-744. URL: http://www.springerlink.com/ index/10.1007/s10584-010-9961-z.

Goeschl, T., Heyen, D., Moreno-Cruz, J., 2013. The intergenerational transfer of solar radiation management capabilities and atmospheric carbon stocks. Environ. Resour. Econ. https://doi.org/10.1007/s10640-013-9647-x.

Gramstad, K., Tjøtta, S., 2010. Climate engineering: cost benefit and beyond. MPRA Paper 27302. University Library of Munich, Germany. URL: http://ideas.repec.org/p/pra/ mprapa/27302.html.

Heutel, G., Moreno-Cruz, J., Ricke, K., 2016. Climate engineering economics. Annu. Rev. Resour. Econ. 8, 99-118. https://doi.org/10.1146/annurev-resource-100815095440.

Irvine, P.J., Kravitz, B., Lawrence, M.G., Gerten, D., Caminade, C., Gosling, S.N., Hendy, E.J., Kassie, B.T., Kissling, W.D., Muri, H., Oschlies, A., Smith, S.J., 2017. Towards a comprehensive climate impacts assessment of solar geoengineering. Earth Fut. 5 (1). https://doi.org/10.1002/2016EF000389/abstract. 2016EF000389.

Klepper, G., Rickels, W., 2012. The real economics of climate engineering. Econ. Res. Int. 2012, 1-20. URL: http://www.hindawi.com/journals/econ/2012/316564/\#B96.

Lempert, R., Schlesinger, M., Bankes, S., Andronova, N., 2000. The impacts of climate variability on near-term policy choices and the value of information. Clim. Change 45 (1), 129-161. https://doi.org/10.1023/A.

Lenton, T.M., Held, H., Kriegler, E., Hall, J.W., Lucht, W., Rahmstorf, S., Schellnhuber, H.J., 2008. Tipping elements in the Earth's climate system. Proc. Natl. Acad. Sci. 105 (6), 1786-1793. URL: http://www.pnas.org/content/105/6/1786.short.

Manoussi, V., Xepapadeas, A., 2015. Cooperation and competition in climate change policies: mitigation and climate engineering when countries are asymmetric. Environ. Resour. Econ. 1-23. https://doi.org/10.1007/s10640-015-9956-3.

Matthews, H.D., Gillett, N.P., Stott, P.A., Zickfeld, K., 2009. The proportionality of global warming to cumulative carbon emissions. Nature 459 (7248), 829-832. URL: http:// www.nature.com/nature/journal/v459/n7248/full/nature08047.html.

McLaren, D., 2016. Mitigation deterrence and the "moral hazard" of solar radiation management. Earth Fut. 4 (12), 596-602. https://doi.org/10.1002/2016EF000445 abstract.

Millard-Ball, A., 2012. The Tuvalu Syndrome. Clim. Change 110 (3), 1047-1066. URL: http://www.springerlink.com/content/r8703842497m5305/abstract/.

Moreno-Cruz, J., Ricke, K., Keith, D., 2012. A simple model to account for regional inequalities in the effectiveness of solar radiation management. Clim. Change 110 (3), 649-668. URL: http://www.springerlink.com/content/x6mr70v78n6p6246/ abstract/.

Moreno-Cruz, J.B., 2015. Mitigation and the geoengineering threat. Resour. Energy Econ. 41, 248-263. URL: http://www.sciencedirect.com/science/article/pii/ S092876551500038X.

Moreno-Cruz, J.B., Keith, D.W., 2013. Climate policy under uncertainty: a case for solar geoengineering. Clim. Change 121 (3), 431-444. https://doi.org/10.1007/s10584012-0487-4.

Moreno-Cruz, J.B., Smulders, S., 2017. Revisiting the economics of climate change the role of geoengineering. Res. Econ. URL: https://www.sciencedirect.com/science/ article/pii/S1090944316302484.

Nordhaus, W., 2014. Estimates of the social cost of carbon: concepts and results from the DICE-2013r model and alternative approaches. J. Assoc. Environ. Resour. Econ. 1 (1/ 2), 273-312. https://doi.org/10.1086/676035.

Nordhaus, W.D., 2017. Revisiting the social cost of carbon. Proc. Natl. Acad. Sci. 20160924400000, URL: http://www.pnas.org/content/early/2017/01/30/ 1609244114.short.

Oschlies, A., Held, H., Keller, D., Keller, K., Mengis, N., Quaas, M., Rickels, W., Schmidt, H., 2017. Indicators and metrics for the assessment of climate engineering. Earth Fut. 5 (1), 49-58. https://doi.org/10.1002/2016EF000449/abstract. 00001.

Quaas, M.F., Quaas, J., Rickels, W., Boucher, O., 2017. Are there reasons against openended research into solar radiation management? A model of intergenerational decision-making under uncertainty. J. Environ. Econ. Manage. 84, 1-17. URL: http:// www.sciencedirect.com/science/article/pii/S0095069617300608.

Rabitz, F., 2016. Going rogue? Scenarios for unilateral geoengineering. Futures 84 (Part A), 98-107. URL: https://www.sciencedirect.com/science/article/pii/ S0016328716300775.

Rayner, S., Heyward, C., Kruger, T., Pidgeon, N., Redgwell, C., Savulescu, J., 2013. The Oxford principles. Clim. Change 121 (3), 499-512. https://doi.org/10.1007/s10584012-0675-2.

Ricke, K.L., Moreno-Cruz, J.B., Caldeira, K., 2013. Strategic incentives for climate geoengineering coalitions to exclude broad participation. Environ. Res. Lett. 8 (1), 014021. URL: http://stacks.iop.org/1748-9326/8/i=1/a =014021?key = crossref. 991d2936c16cded8b7e89da7e930d268.

Rogelj, J., Luderer, G., Pietzcker, R.C., Kriegler, E., Schaeffer, M., Krey, V., Riahi, K., 2015. Energy system transformations for limiting end-of-century warming to below 1.5c. Nat. Clim. Change 5 (6), 519-527. https://doi.org/10.1038/nclimate2572.

Russell, L.M., Rasch, P.J., Mace, G.M., Jackson, R.B., Shepherd, J., Liss, P., Leinen, M., Schimel, D., Vaughan, N.E., Janetos, A.C., Boyd, P.W., Norby, R.J., Caldeira, K., Merikanto, J., Artaxo, P., Melillo, J., Morgan, M.G., 2012. Ecosystem impacts of geoengineering: a review for developing a science plan. Ambio 41 (4), 350-369. URL: 
http://www.ncbi.nlm.nih.gov/pmc/articles/PMC3393062/.

Schelling, T.C., 1996. The economic diplomacy of geoengineering. Clim. Change 33 (3), 303-307. URL: http://www.springerlink.com/content/m6nnw1k37075qh51/ abstract/.

Sterck, O., 2011. Geoengineering as an alternative to mitigation: specification and dynamic implications. Tech. Rep.

UNEP, 2010. The Emission Gap Report 2010: Are the Copenhagen Pledges Sufficient to Limit Global Warming to $2 \mathrm{c}$ or $1.5 \mathrm{c}$ ? Tech. Rep. UN Environment Programme, Nairobi.

Urpelainen, J., 2012. Geoengineering and global warming: a strategic perspective. Int.
Environ. Agree.: Polit. Law Econ. 12 (4), 375-389. https://doi.org/10.1007/s10784012-9167-0.

Victor, D.G., Morgan, M.G., Apt, J., Steinbruner, J., Ricke, K., 2009. The geoengineering option: a last resort against global warming? Foreign Affairs 88 (2), 64-76.

Virgoe, J., 2008. International governance of a possible geoengineering intervention to combat climate change. Clim. Change 95 (1-2), 103-119. https://doi.org/10.1007/ s10584-008-9523-9.

Weitzman, M.L., 2015. A voting architecture for the governance of free-driver externalities, with application to geoengineering. Scand. J. Econ. 117 (4), 1049-1068. https://doi.org/10.1111/sjoe.12120. 